\title{
Zn-Fe multilayered alloy coatings produced by electrodeposition
}

\author{
Christos N. Panagopoulos ${ }^{1} \cdot$ Konstantinos G. Georgarakis ${ }^{1} \cdot$ Konstantinos I. Giannakopoulos $^{1,2}$
}

(c) Springer Nature Switzerland AG 2018

\begin{abstract}
$\mathrm{Zn}$-Fe multilayered alloy coatings were deposited on mild steel substrates using the dual bath electrodeposition technique. The produced coatings consisted of alternate $\mathrm{Zn}-1 \mathrm{wt} \% \mathrm{Fe}$ and $\mathrm{Zn}-10 \mathrm{wt} \%$ Fe alloy sub-layers. Their periodicity length (total thickness of two adjacent alternate sub-layers) ranged between 2 and $8 \mu \mathrm{m}$. The surface and the crosssectional morphology of those coatings were studied with the aid of a metallurgical microscope and a scanning electron microscope. The crystal structure of the electrodeposited multilayered coatings was investigated using an X-ray diffractometer. The Zn-1 wt\% Fe and Zn-10 wt\% Fe alloy sub-layers consisted of two phases: the $n$-phase (Zn-Fe solid solution) and the $\delta_{1}$-phase (intermetallic FeZn $n_{7}$ ). A microhardness tester equipped with a Vickers intender was used to examine the microhardness of the produced coatings. It was found that the microhardness increased with the decrease of periodicity length, following a modified Hall-Petch relationship.
\end{abstract}

Keywords Electroplating $\cdot$ Multilayer $\cdot$ Zinc alloy $\cdot$ Scanning electron microscopy $($ SEM) $\cdot$ X-ray diffraction $\cdot$ Vickers hardness test

\section{Introduction}

Multilayered coatings have attracted considerable attention of several investigators during the last decade, mainly because of their improved mechanical, physical and/or electrochemical properties. Furthermore, the possibility of tailoring the structure of those materials in conformity with the demands of certain mechanical, optical and electrochemical applications, has led to increased flexibility in materials design. However, due to their complex structure, multilayered coatings usually demand a great number of parameters to be determined for a detailed characterization of their structure including the structural and chemical periodicity, the crystallography of the sublayers, the surface and interface roughness and the coherency between the sub-layers [1-3].

$Z n$ alloy single-layered electrodeposited coatings (such as $\mathrm{Zn}-\mathrm{Ni}, \mathrm{Zn}-\mathrm{Co}$ and $\mathrm{Zn}-\mathrm{Fe}$ coatings) have been extensively studied [4-9]. It has been shown that these coatings present very good anticorrosive properties, providing enhanced corrosion protection of ferrous substrates [9-14] and improved tribological behavior in comparison to the pure $\mathrm{Zn}$ electrodeposited coatings [15-17]. Therefore, $\mathrm{Zn}$ alloy coatings have been used in several industrial sectors including the automotive industry. Recent investigations though, have shown that multilayered coatings consisting of $\mathrm{Zn}$ alloy sub-layers may perform better as corrosion resistant coatings than equivalent single-layered coatings. Up to date, multilayered coatings consisting of pure $\mathrm{Zn}$ and $\mathrm{Ni}$ layers and $\mathrm{Zn}-\mathrm{Ni}$ multilayered alloy coatings were produced with the aid of dual-bath and single-bath electrodeposition techniques [18-21]. The surface morphology and the corrosion behavior of those coatings have been studied and improved corrosion resistance of multilayered coatings in comparison to equivalent single-layered coatings has been reported. Investigations dealing with the morphological characteristics and the corrosion behavior of electrodeposited $\mathrm{Zn}$-Co multilayered coatings have also

$\triangle$ Konstantinos I. Giannakopoulos, kgiannakopoulos@teipir.gr| ' Laboratory of Physical Metallurgy, National Technical University of Athens, 15780 Zografos, Athens, Greece. ${ }^{2}$ Laboratory of Strength of Materials, Technological Institute of Piraeus, 12244 Aegaleo, Greece.

SN Applied Sciences (2019) 1:114 | https://doi.org/10.1007/s42452-018-0120-x 
been reported [22-24]. It has been shown that Zn-Co multilayered alloy coatings present better corrosion resistance than equivalent single-layered coatings. For the case of $\mathrm{Zn}$-Fe multilayered coatings, the literature is limited and more concentrated in Zn-Fe multilayered alloy coatings produced by the single bath electrodeposition technique $[25,26]$. In these studies $[25,26]$, special attention has been given in the understanding of the anomalous codeposition mechanism in $\mathrm{Zn}$-Fe alloy electroplating and it has been suggested that the $\mathrm{Zn}$ based alloy multilayered coatings offer a combination of sacrificial and barrier corrosion protection to mild steel substrates.

During the past few years, may investigations have been published dealing with the multilayer coatings and their improved tribological properties, their corrosion resistance and many other surface properties [27-38]. In the present study, new Zn-Fe multilayered alloy coatings were deposited on mild steel substrates using the dual bath electrodeposition technique. The surface and crosssectional morphology, the crystal structure, the surface roughness and the microhardness of $\mathrm{Zn}-\mathrm{Fe}$ multilayered alloy coatings were investigated.

\section{Materials and methods}

Mild steel specimens with dimensions $40 \times 20 \times 0.5 \mathrm{~mm}^{3}$ were cut from a mild steel sheet, Table 1, machined to an average roughness $(\mathrm{Ra})$ of $0.3 \mu \mathrm{m}$ and annealed at $550^{\circ} \mathrm{C}$ for $2 \mathrm{~h}$ in an Ar-inert atmosphere.

After the stress-relief annealing, the specimens were left to cool inside the furnace until the temperature in the furnace araised $50^{\circ} \mathrm{C}$. Annealing was followed by cleaning with acetone in an ultrasonic bath for $25 \mathrm{~min}$., rinsing by deionized water, activation in a proprietary solution consisted of $\mathrm{HCl}$ and various corrosion inhibitors and rinsing by deionized water. The mild steel specimens were then used as substrates for the deposition of $\mathrm{Zn}$-Fe multilayered alloy coatings with the aid of the dual bath electrodeposition technique (DBT). The two solutions used in this study, Table 2, consisted of the same salts in different concentrations. Solution 1 was leading to the electrodeposition of $\mathrm{Zn}-1 \mathrm{wt} \%$ Fe alloy layers, while solution 2 was leading to the electrodeposition of Zn-10wt\% Fe alloy layers. Alternating $\mathrm{Zn}-1 \mathrm{wt} \% \mathrm{Fe}$ and $\mathrm{Zn}-10 \mathrm{wt} \%$ Fe alloy layers were deposited on the steel substrates, in order to produce a variety of multilayered alloy coatings, Table 3 .

The surface and the cross sectional morphology of the produced $\mathrm{Zn}-\mathrm{Fe}$ multilayered alloy coatings were examined with the aid of a Jevanert metallurgical microscope (MM), a Jeol 6100 scanning electron microscope (SEM) equipped with a Noran TS 5500 energy dispersive
Table 1 Chemical composition (wt\%) of mild steel substrates

\begin{tabular}{lllllllll}
\hline $\mathrm{C}$ & $\mathrm{Si}$ & $\mathrm{Mn}$ & $\mathrm{P}$ & $\mathrm{S}$ & $\mathrm{Cr}$ & $\mathrm{Ni}$ & $\mathrm{Mo}$ & $\mathrm{V}$ \\
0.0705 & 0.0157 & 0.3580 & 0.0128 & 0.0139 & 0.0155 & 0.0169 & 0.0017 & 0.0013 \\
$\mathrm{Co}$ & $\mathrm{Sn}$ & $\mathrm{Al}$ & $\mathrm{Yi}$ & $\mathrm{As}$ & $\mathrm{B}$ & $\mathrm{Nb}$ & $\mathrm{Cu}$ & $\mathrm{Fe}$ \\
0.0039 & 0.0020 & 0.0348 & 0.0010 & 0.0020 & 0.0005 & 0.0020 & 0.0078 & 99.44 \\
\hline
\end{tabular}

Table 2 Chemical composition of electrodeposition baths and electrodeposition parameters

\begin{tabular}{lll}
\hline & Solution 1 & Solution 2 \\
Composition of electrodeposition baths (g/l) & & 405 \\
\hline $\mathrm{ZnSO}_{4} \cdot 7 \mathrm{H}_{2} \mathrm{O}$ & 97 & 68 \\
$\mathrm{FeSO}_{4} \cdot 7 \mathrm{H}_{2} \mathrm{O}$ & 342 & 141 \\
$\mathrm{Na}_{2} \mathrm{SO}_{4}$ & 141 & 0.05 \\
$\mathrm{CuSO}_{4}$ & 0.10 & Bath 2 \\
\hline & Bath 1 & \\
Electrodeposition parameters & & $40 \pm 2{ }^{\circ} \mathrm{C}$ \\
\hline Temperature & $40 \pm 2{ }^{\circ} \mathrm{C}$ & Stainless steel \\
Anodes & Stainless steel & $30 \mathrm{~mA} / \mathrm{cm}^{2}$ \\
Current density & $30 \mathrm{~mA} / \mathrm{cm}^{2}$ & 1.5 \\
pH & 1.5 & \\
\hline
\end{tabular}

SN Applied Sciences 
Table 3 Characteristics of the produced Zn-Fe multilayered alloy coatings

\begin{tabular}{llll}
\hline & Periodicity length & Sub-layers & Total thickness \\
\hline ML 1 & $2 \mu \mathrm{m}$ & {$[1 \mu \mathrm{m}(\mathrm{Zn}-1 \% \mathrm{Fe})+1 \mu \mathrm{m}(\mathrm{Zn}-10 \% \mathrm{Fe})]_{10}$} & $20 \mu \mathrm{m}$ \\
$\mathrm{ML} 2$ & $4 \mu \mathrm{m}$ & {$[2 \mu \mathrm{m}(\mathrm{Zn}-1 \% \mathrm{Fe})+2 \mu \mathrm{m}(\mathrm{Zn}-10 \% \mathrm{Fe})]_{5}$} & $20 \mu \mathrm{m}$ \\
$\mathrm{ML} 3$ & $6 \mu \mathrm{m}$ & {$[4 \mu \mathrm{m}(\mathrm{Zn}-1 \% \mathrm{Fe})+2 \mu \mathrm{m}(\mathrm{Zn}-10 \% \mathrm{Fe})]_{8}$} & $48 \mu \mathrm{m}$ \\
$\mathrm{ML} 4$ & $8 \mu \mathrm{m}$ & {$[6 \mu \mathrm{m}(\mathrm{Zn}-1 \% \mathrm{Fe})+2 \mu \mathrm{m}(\mathrm{Zn}-10 \% \mathrm{Fe})]_{4}$} & $32 \mu \mathrm{m}$
\end{tabular}

spectrometer (EDS) and an Image Pro image analysis system. The crystal structure of the same coatings was investigated using a Siemens D $5000 \mathrm{X}$-ray diffractometer (XRD) with $\mathrm{Cu} \mathrm{K}_{\mathrm{a}}$ radiation and a graphite monochromator. Zn-1wt\% Fe and Zn-10wt\% Fe single-layered coatings with $5 \mu \mathrm{m}$ and $10 \mu \mathrm{m}$ thickness were also electrodeposited on mild steel substrates from baths 1 and 2 respectively, and examined with the X-ray diffractometer in order to supplement the crystallographic investigation of the produced $\mathrm{Zn}-\mathrm{Fe}$ multilayered alloy coatings. The average grain size was estimated using the Debye-Schrerrer relation [39].

The average surface roughness ( $\mathrm{Ra}$ ) of the produced $\mathrm{Zn}$-Fe multilayered alloy coatings was studied with the aid of a Time TR $230 \mathrm{VDH}$ profilometer. Eleven (11) surface roughness measurements in random directions were performed on the surface of each multilayered coating. The microhardness of the $\mathrm{Zn}-\mathrm{Fe}$ multilayered alloy coatings was investigated with the aid of a Shimadzu HMV 2000 microhardness tester equipped with a Vickers indenter. Microhardness measurements were carried out on the surface and in the cross section of the produced coatings. The applied load was $10 \mathrm{~g}$ for $15 \mathrm{~s}$. For the selected applied load, any substrate effects on the hardness of the multilayered coatings were avoided, since the maximum indentation depth was smaller than the one-tenth of the coatings thickness, which is the threshold value for the substrate interference in coating's thickness [40].

\section{Results and discussion}

All the $\mathrm{Zn}-\mathrm{Fe}$ multilayered coatings investigated in the present study had as top-layer (near the surface sublayer) a Zn-10wt\% Fe alloy sub-layer. Surface micrographs of the produced $\mathrm{Zn}-\mathrm{Fe}$ multilayered alloy coatings are presented in Fig. 1a-d. As can be seen in those figures, the surface morphology of the produced multilayered coatings showed a typical nodular structure. The size of the formed nodules was observed to be smaller in Fig. 1 a (periodicity length: $2 \mu \mathrm{m}, \mathrm{ML} 1$ ) than that in Fig. $1 b-d$ (periodicity lengths: $4-8 \mu m, M L 2, M L 3, M L 4)$.
Fig. 1 SEM surface micrographs of $\mathrm{Zn}$-Fe multilayered alloy coatings with periodicity lengths: a $2 \mu \mathrm{m}(\mathrm{ML} 1)$, b $4 \mu \mathrm{m}$ (ML2), c $6 \mu \mathrm{m}(\mathrm{ML} 3)$ and $\mathbf{d}$ $8 \mu \mathrm{m}(\mathrm{ML} 4)$
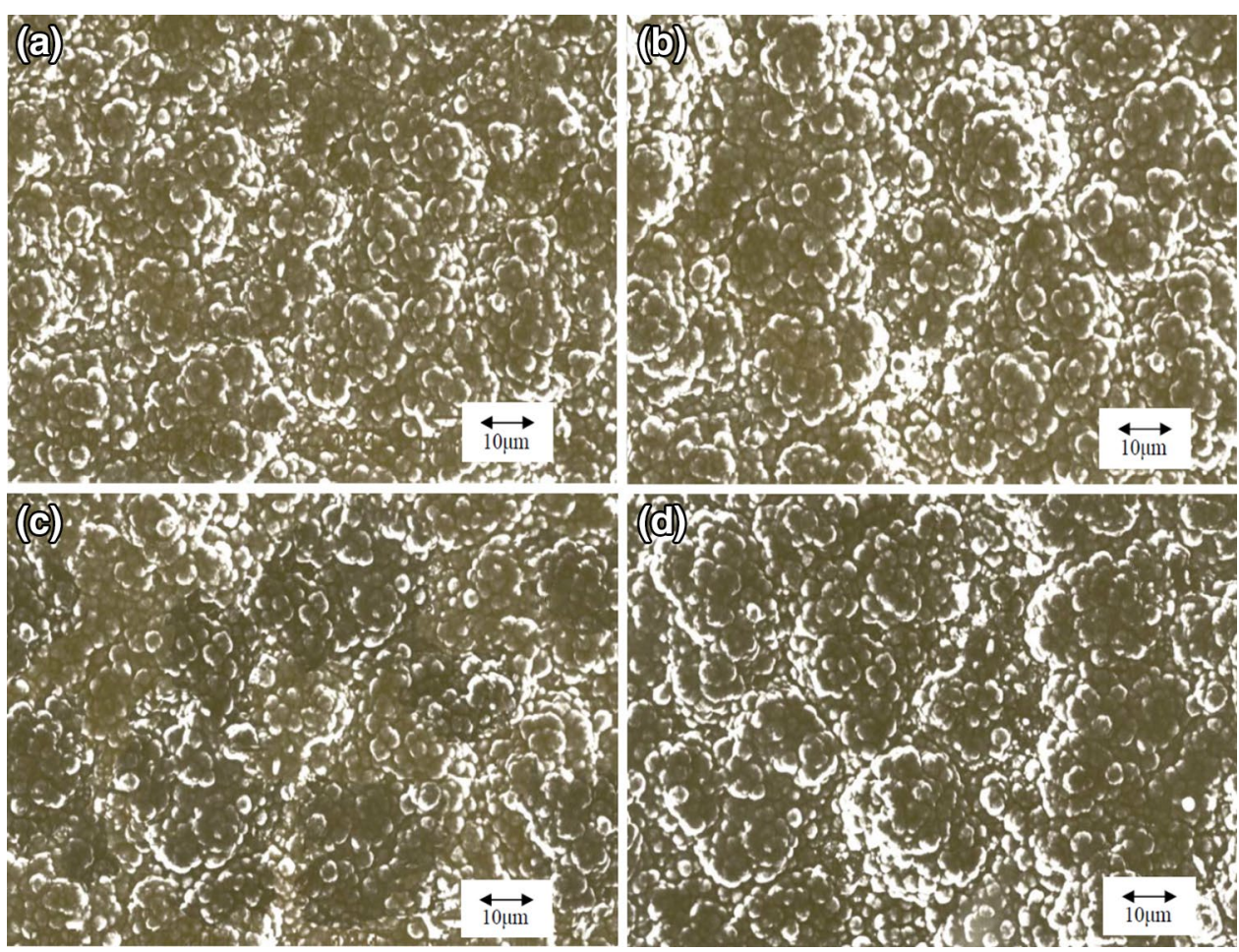
The above observation could be attributed to the lower top-layer thickness $(1 \mu \mathrm{m})$ of the multilayered coating shown in Fig. 1 a (periodicity length: $2 \mu \mathrm{m}, \mathrm{ML} 1$ ), in comparison to the top-layer thickness $(2 \mu \mathrm{m})$ of multilayered coatings shown in Fig. 1b-d (periodicity lengths: 4-8 $\mu \mathrm{m}$, ML2, ML3, ML4). Based on the above observations, it could be suggested that the surface morphology of the produced $\mathrm{Zn}$-Fe multilayered coatings was directly influenced by the top-layer thickness and indirectly connected to their periodicity length (total thickness of two adjacent alternate sub-layers).

Figure 2a-d show the surface morphology of the $\mathrm{Zn}-\mathrm{Fe}$ multilayered alloy coatings after metallographic preparation (polishing and chemical etching). In these figures, the presence of two different areas can be observed. The light colour areas correspond to $\eta$-phase ( $Z n-F e$ solid solution) and the dark colour areas correspond to $\delta_{1}$ phase (intermetallic FeZn $\mathrm{n}_{7}$ ). Quantitative investigations performed on coatings surfaces showed that the light colour areas ( $n$-phase solid solution) covered the $60-65 \%$ of the surface, while the dark colour areas $\left(\delta_{1}\right.$-phase, intermetallic FeZn $n_{7)}$ covered the $40-35 \%$ of the coatings surface.
Cross sectional micrographs of the $\mathrm{Zn}$-Fe multilayered alloy coatings are presented in Fig. $3 a-d$. As it can be observed, the $\mathrm{Zn}-1$ wt\% Fe and $\mathrm{Zn}-10$ wt\% Fe alloy sub-layers were continuous, without detectable cracks or other flaws. The chemical composition of each sub-layer was measured with the aid of an EDS apparatus connected to the SEM. Observing the interfaces between the $\mathrm{Zn}-1 \mathrm{wt} \%$ Fe and $\mathrm{Zn}-10 \mathrm{wt} \%$ Fe sub-layers the absence of noticeable pores, cracks or other discontinuities can also be noticed, indicating good adhesion between the alloy sub-layers. Interface roughness was observed between the $\mathrm{Zn}-1$ wt\% Fe and $\mathrm{Zn}-10$ wt\% Fe alloy sub-layers. This observation could be attributed to the surface roughness of each Zn-1 wt\% Fe and Zn-10 wt\% Fe alloy sub-layer, which was formed during the electrodeposition of those layers. Interface roughness is believed to contribute to the interface adhesion between the alloy sub-layers, although in some cases (if it is too high), could lead to unfavourable high surface roughness.

Figure $4 \mathrm{a}$ and $\mathrm{b}$ show the $\mathrm{X}$-ray diffraction spectra taken from the $\mathrm{Zn}-1 \mathrm{wt} \%$ Fe and $\mathrm{Zn}-10 \mathrm{wt} \%$ Fe singlelayered coatings respectively. In Fig. $4 a(Z n-1$ wt $\%$ Fe

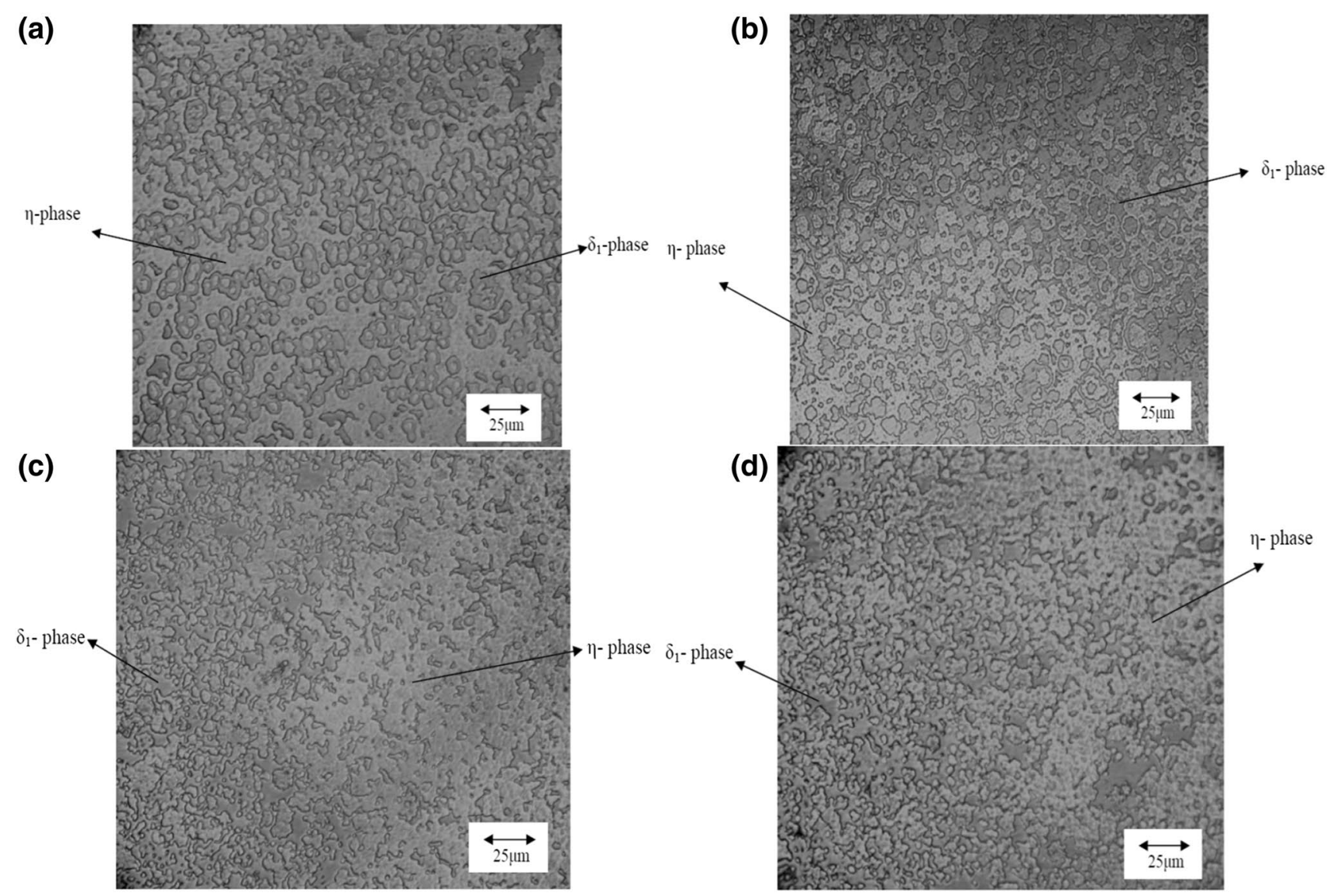

Fig. 2 Surface morphology of Zn-Fe multilayered alloy coatings with periodicity lengths: a $2 \mu \mathrm{m}(\mathrm{ML} 1)$, b $4 \mu \mathrm{m}(\mathrm{ML} 2)$, c $6 \mu \mathrm{m}$ (ML3) and d $8 \mu \mathrm{m}$ (ML4), after metallographic preparation (polishing and chemical etching). MM micrographs 
(a)

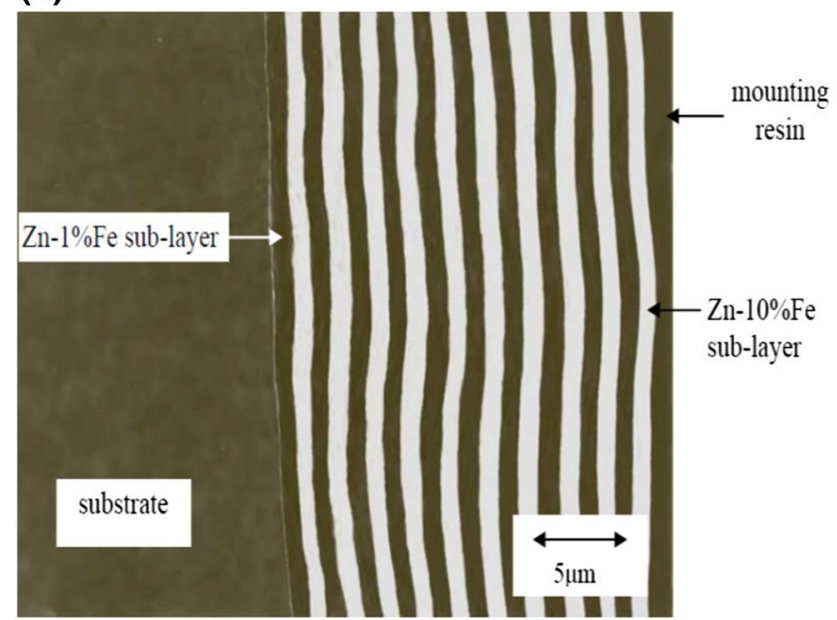

(c)

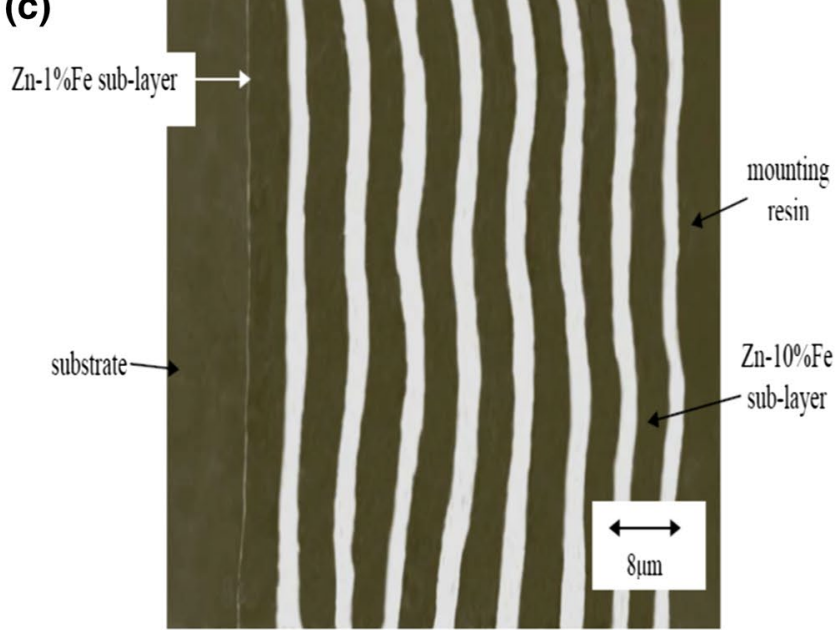

(b)

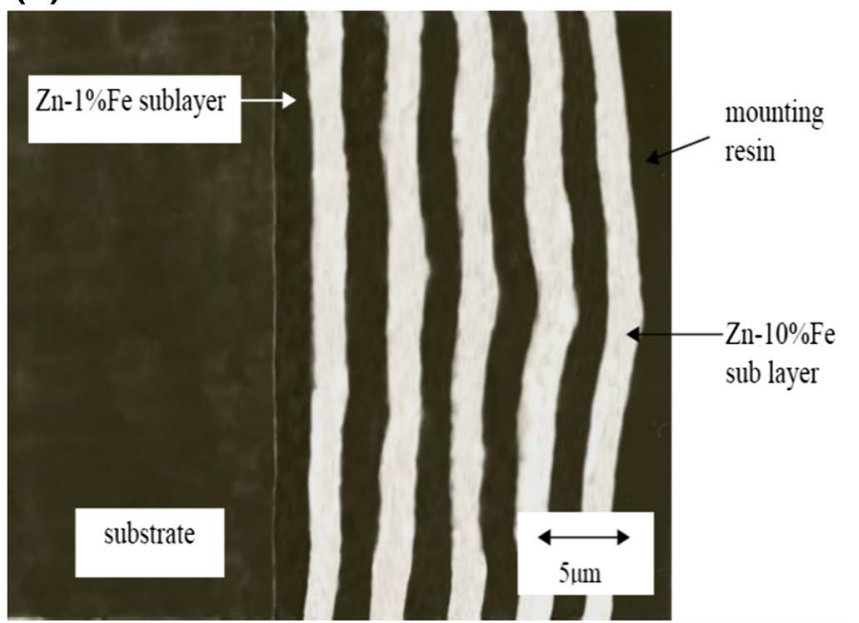

(d)

Zn- $1 \%$ Fe sub-layer
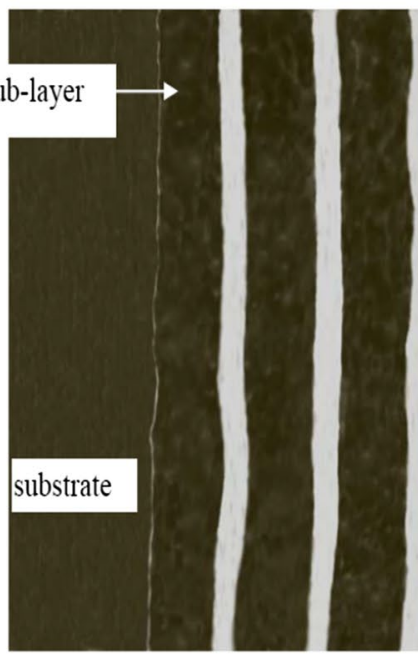

Fig. 3 Cross sectional morphology of Zn-Fe multilayered alloy coatings with periodicity lengths: a $2 \mu \mathrm{m}(\mathrm{ML} 1)$, b $4 \mu \mathrm{m}$ (ML2), c $6 \mu \mathrm{m}$ (ML3) and d $8 \mu \mathrm{m}$ (ML4). SEM micrographs

coating), the detected XRD peaks corresponding to $\eta$-phase ( $Z n-F e$ solid solution) can be mainly observed. In the same figure (Fig. 4a), some small XRD peaks corresponding to $\delta_{1}$-phase (intermetallic FeZ $n_{7}$ ) can also be noticed. In Fig. 4b (Zn-10 wt\% Fe coating), XRD peaks corresponding to both $\eta$-phase ( $\mathrm{n} n-\mathrm{Fe}$ solid solution) and $\delta_{1}$-phase (intermetallic FeZn $n_{7}$ ) can be observed. The intensity of $\delta_{1}$-phase XRD peaks in Fig. $4 \mathrm{~b}$ (Zn-10 wt\% Fe coating), was noted to be higher in comparison to their intensity in Fig. $4 a$ ( $Z n-1$ wt\% Fe coating). Furthermore, the intensity of $\eta$-phase XRD peaks shown in Fig. 4b ( $Z n-10 w t \%$ Fe coating) was observed to be lower compared to their intensity in Fig. $4 a(\mathrm{Zn}-10 \mathrm{wt} \%$ Fe coating). The above observation could be considered as a clear evidence for the higher concentration of $\delta_{1}$ intermetallic phase in $\mathrm{Zn}-10$ wt\% Fe layers in comparison to the concentration of the same phase $\left(\delta_{1}\right.$-phase) in $\mathrm{Zn}-1$ wt\% Fe layers. It should be noted that $\eta$-phase corresponds to the $\mathrm{Zn}$-Fe solid solution with maximum solubility of 0.2 at.\% Fe and hexagonal close packed (hcp) crystal structure, while $\delta_{1}$-phase is an intermetallic phase $\left(\mathrm{FeZn}_{7}\right)$, which also has hexagonal close packed (hcp) crystal structure.

Figure 5a-d show XRD spectra taken from the produced $\mathrm{Zn}$-Fe multilayered alloy coatings. In these figures, XRD peaks corresponding to $\eta$-phase (solid solution) and $\delta_{1^{-}}$ phase (intermetallic $\mathrm{FeZn}_{7}$ ) can be observed. Comparing the spectra from Figs. 4 and 5, it is strongly believed that the crystallographic information shown in the $\mathrm{Zn}-\mathrm{Fe}$ multilayered alloy coatings XRD spectra (Fig. 5) originates from several $\mathrm{Zn}-10 \mathrm{wt} \%$ Fe and $\mathrm{Zn}-1 \mathrm{wt} \%$ Fe sub-layers and not only from the top Zn-10 wt\% Fe layer. In XRD patterns (Figs. $4 b, 5 c$ ) there are many very minor peaks that are not assigned. This noise may be attributed to the fact that the $X$-ray beam penetrates deeper than the thickness of the upper layer. This leads to the fact the X-ray diffractometers 
Fig. 4 X-ray diffraction patterns taken from a $\mathrm{Zn}-1 \mathrm{wt} \% \mathrm{Fe}$ and $\mathbf{b} \mathrm{Zn}-10$ wt\% Fe single-layered alloy coatings. Where $n$ : $\eta$-phase (Zn-Fe solid solution) and $\delta_{1}: \delta_{1}$-phase (intermetallic $\mathrm{Fe} Z \mathrm{Zn}_{7}$ )
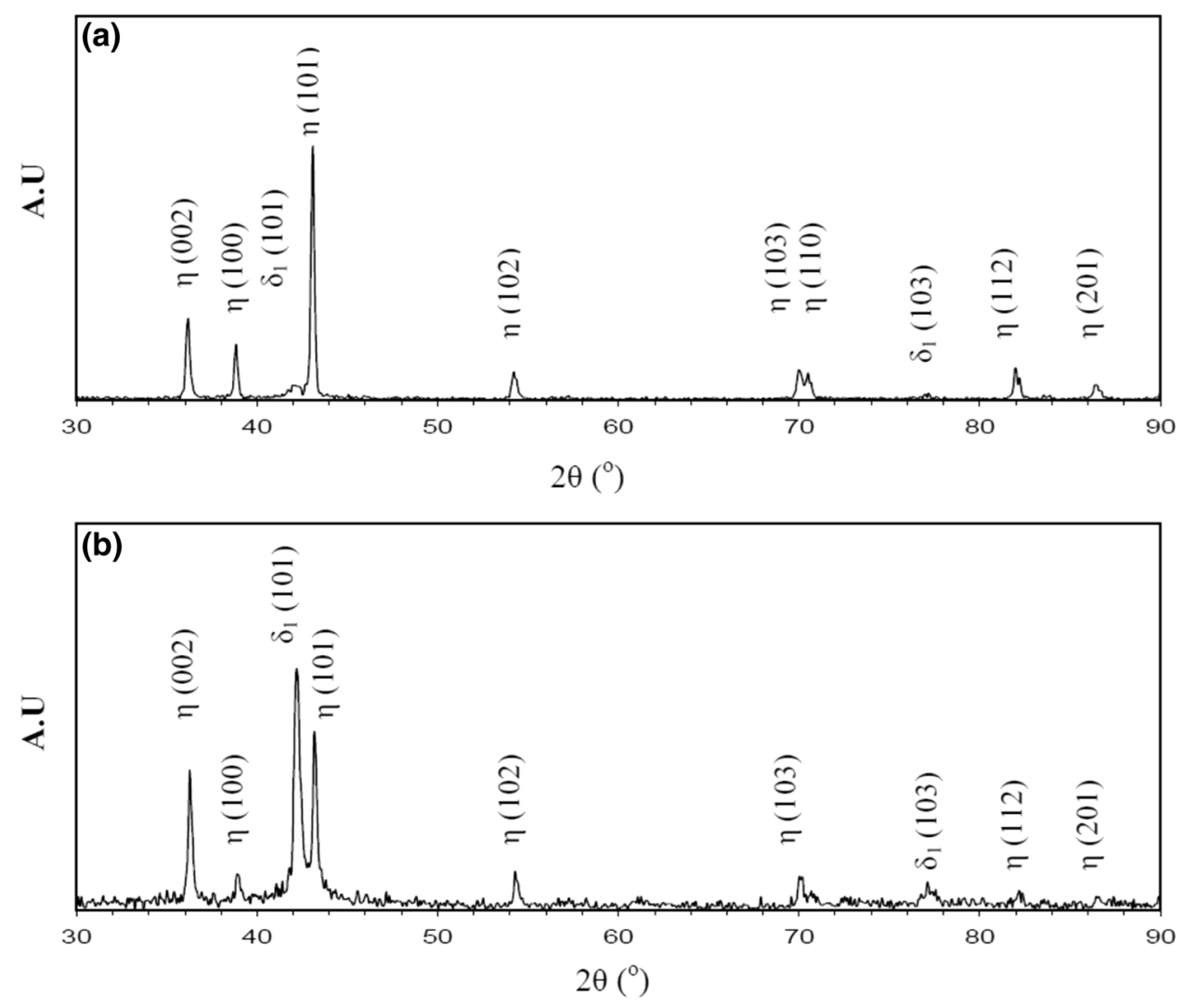

are enriched with some very small peaks that may be attributed to the interface of the two layers.

According to the equilibrium phase diagram, Fig. 6, the $\mathrm{Zn}-1$ wt\% Fe sub-layer would be expected to consist of $\eta$-phase ( $Z n-F e$ solid solution) and $\zeta$-phase (intermetallic $\mathrm{Fe}-\mathrm{Zn}_{13}$ ), while $\mathrm{Zn}-10$ wt\% Fe sub-layer would be expected to consist only of $\delta_{1}$-phase(intermetallic $\mathrm{Fe}-\mathrm{Zn}_{7}$ ). However, based on the above observations from the XRD analysis (Figs. 4, 5), it could be suggested that the electrodeposited $\mathrm{Zn}$-Fe multilayered alloy coatings do not follow the $\mathrm{Fe}-\mathrm{Zn}$ equilibrium phase diagram, confirming previous results which support the predominance of non-equilibrium conditions during the electrodeposition of Zn-Fe alloy coatings [39-42].

The average grain size of the $\mathrm{Zn}-\mathrm{Fe}$ multilayered alloy coatings was estimated using the well-known Debye-Schrerrer relation (1) from the XRD analysis:

$\delta=\frac{\kappa \lambda}{B \cos \theta}$

where $\delta$ is the average grain size, $B$ is the Full Width at Half Maximum (FWHM), $\theta$ is the Bragg's angle, $\lambda$ is the $X$-ray wavelength and $K$ is a constant [39]. Figure 7 presents the average grain size alloy as a function of the periodicity length of the studied $\mathrm{Zn}-\mathrm{Fe}$ multilayered coatings. The average grain size was found in the range of $40-55 \mathrm{~nm}$, being in agreement with previously reported results for $\mathrm{Zn}-\mathrm{Fe}$ alloy electrodeposits [41, 42]. As can be observed in Fig. 7, the average grain size of Zn-Fe multilayered alloy coatings decreased slightly with the decrease of their periodicity length.

Figure 8 shows the surface roughness (Ra) of the studied $\mathrm{Zn}$-Fe multilayered alloy coatings as a function of their periodicity length. The surface roughness of the multilayered coatings was found to increase with the increase of their periodicity length. The observed increase of the surface roughness might be due to the increase of $Z n-1$ wt $\%$ Fe and $Z n-10$ wt\% Fe sub-layers thickness. It has been shown that increasing the thickness of $Z n$ alloy coatings leads to increased surface roughness. The above observation is believed to be connected to the observed (Fig. 2) increase of the surface nodules size with increasing multilayered coatings periodicity length.

Figure 9a presents the microhardness of the produced $\mathrm{Zn}$-Fe multilayered alloy coatings as a function of their periodicity length. As it can be observed, the microhardness increased from 99 to 151 HVN as the periodicity length of the produced coatings decreased from 8 to $2 \mu \mathrm{m}$. These values were noticed to be higher than the microhardness of single $\mathrm{Zn}-1$ wt $\%$ Fe alloy layers ( $60 \mathrm{HVN}$ ) and lower than the microhardness of $\mathrm{Zn}-10 \mathrm{wt} \%$ Fe alloy layers ( $165 \mathrm{HVN}$ ). It also must be said that the values of 

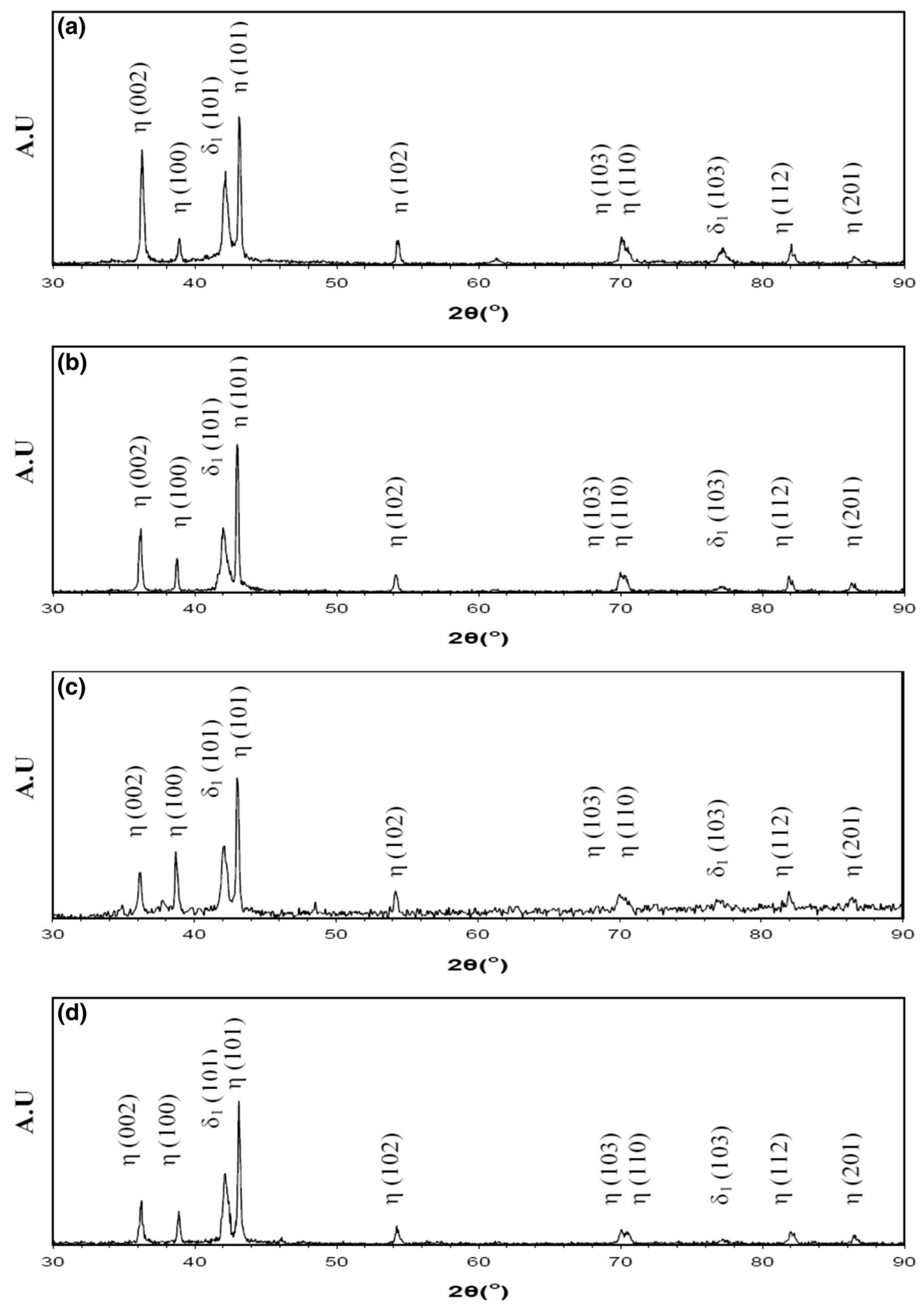

Fig. 5 X-ray diffraction patterns taken from Zn-Fe multilayered alloy coatings with periodicity lengths: a $2 \mu \mathrm{m}(\mathrm{ML} 1)$, b $4 \mu \mathrm{m}$ (ML2), c $6 \mu \mathrm{m}$ (ML3) and $\mathbf{d} 8 \mu \mathrm{m}$ (ML4). Where $\eta$ : $\eta$-phase (solid solution) and $\delta_{1}: \delta_{1}$-phase (intermetallic Fe $Z n_{7}$ ) 


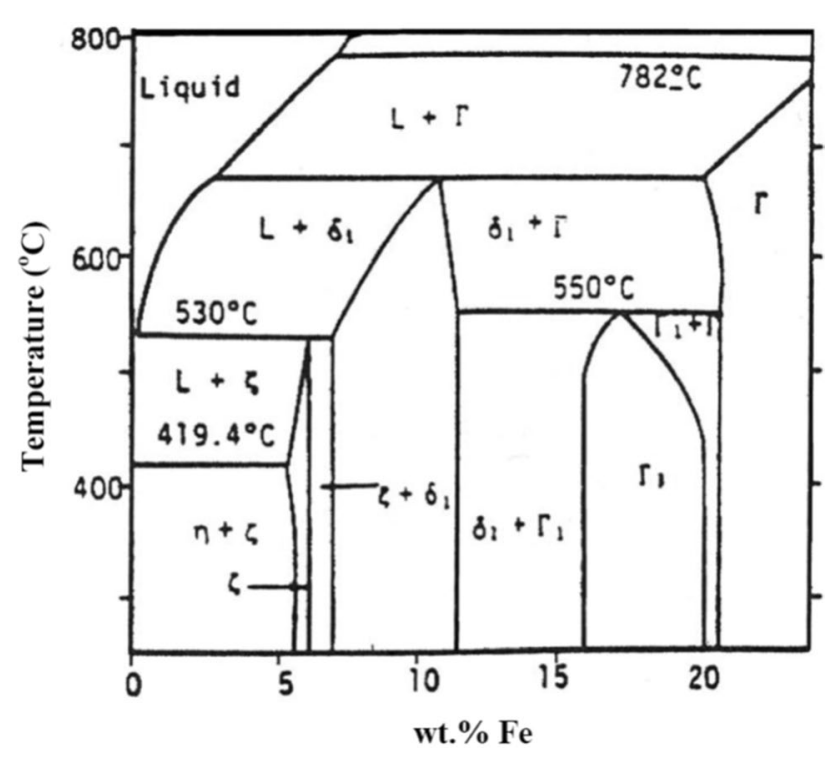

Fig. 6 Fe-Zn equilibrium phase diagram [37]

the microhardness were estimated on the surface of the upper layer. The diamond indenter penetrated in the surface layer but it might reach the inner layer with the different chemical composition. This leads to the assumption that the microhardness values are not responding only to the surface layer of the multilayer coating. The above mentioned Zn-Fe composite multilayered coatings microhardness results were found to be well described $\left(R^{2}=0.98\right)$ by a modified Hall-Petch relationship (2), as shown in Fig. $9 \mathrm{~b}$ :

$\mathrm{H}=\mathrm{H}_{\mathrm{o}}+\mathrm{K} \Lambda^{(-1 / 2)}$

where $\mathrm{H}$ is the hardness of the $\mathrm{Zn}-\mathrm{Fe}$ multilayered alloy coatings, $\Lambda(\mu \mathrm{m})$ is the half of their periodicity length, $K$ and $\mathrm{H}_{\mathrm{o}}$ are constants. The last relation was found to hold for the range of $0.5 \leq \Lambda^{-1 / 2} \leq 0.1$. The observed increase of the multilayered coatings microhardness could be attributed to the presence of the interfaces between the $\mathrm{Zn}-1 \mathrm{wt} \%$ Fe and $\mathrm{Zn}-10 \mathrm{wt} \%$ Fe alloy sub-layers. The interfaces are considered to act in a similar way as grain boundaries in the Hall-Petch model, pilling up the dislocations and thus obstructing to their movement. The increase of interfaces number and the decrease of the distance between them, which were achieved by decreasing the multilayered coatings periodicity length, can lead to increased plastic deformation resistance and higher microhardness values. The values of $M$.

\section{Conclusions}

In the present study, the surface and the cross-sectional morphology, the crystal structure, and the microhardness of $\mathrm{Zn}$-Fe multilayered alloy coatings electrodeposited on mild steel substrates were investigated. The main conclusions were the following:

1. Zn-Fe multilayered alloy coatings with periodicity length ranging between 2 and $8 \mu \mathrm{m}$ were deposited. They consisted of $\mathrm{Zn}-1 \mathrm{wt} \% \mathrm{Fe}$ and $\mathrm{Zn}-10 \mathrm{wt} \% \mathrm{Fe}$ alternate alloy sub-layers.

2. The surfaces of the produced coatings were observed to have nodular structure. The cross section observations indicated that the multilayered coatings were free of noticeable pores, cracks or other discontinuities.

3. XRD investigations revealed the presence of $\eta$-phase (solid solution) and $\delta_{1}$-phase (intermetallic FeZn $n_{7}$ ) in the structure of $\mathrm{Zn}-\mathrm{Fe}$ multilayered alloy coatings.
Fig. 7 Average grain size of $\mathrm{Zn}$-Fe multilayered alloy coatings as a function of their periodicity length

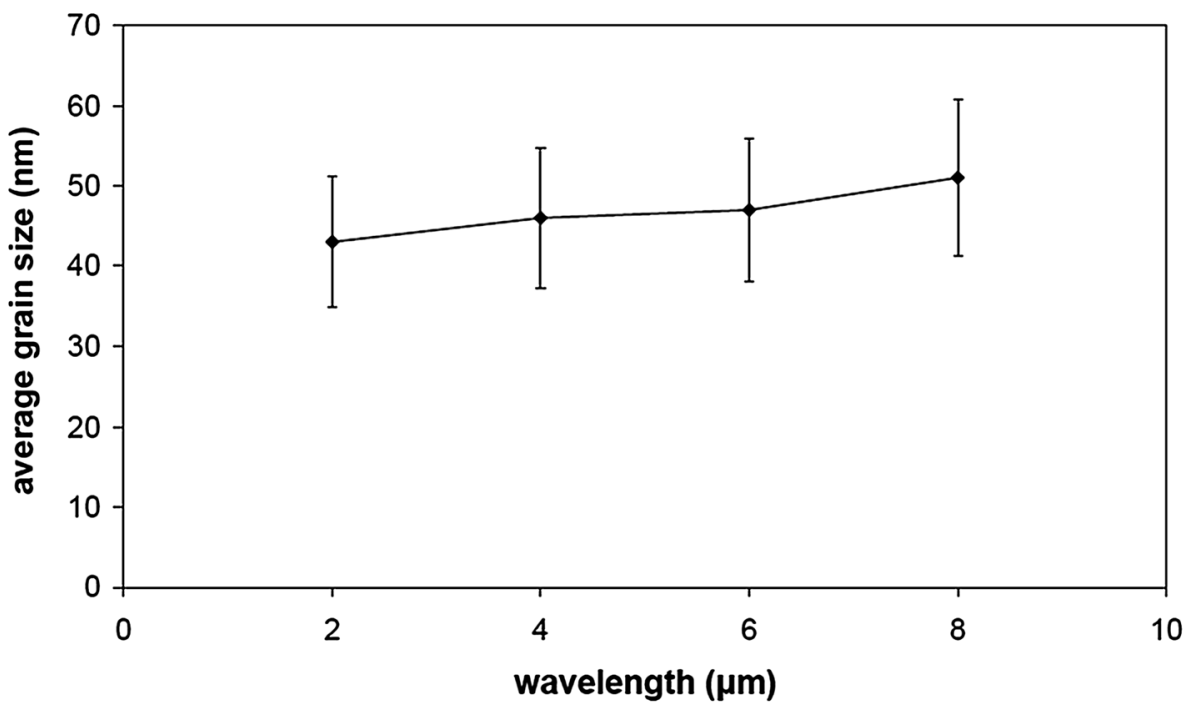


Fig. 8 Average surface roughness (Ra) of $\mathrm{Zn}$-Fe multilayered alloy coatings as a function of their periodicity length
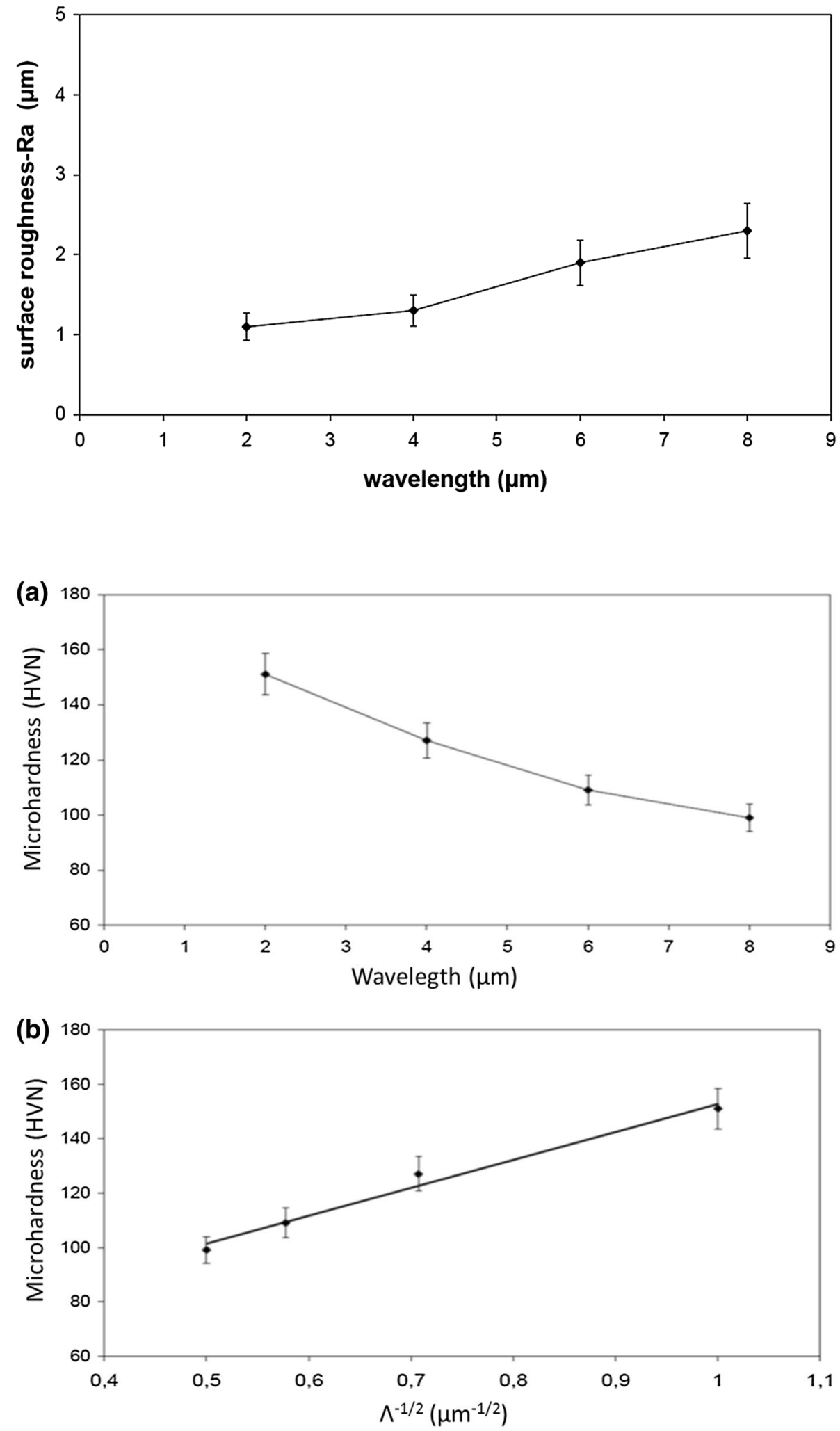

Fig. 9 a Microhardness of the $\mathrm{Zn}$-Fe multilayered alloy coatings as a function of their periodicity length, $\mathbf{b}$ Microhardness of $\mathrm{Zn}$-Fe multilayered alloy coatings as a function of $\Lambda^{(-1 / 2)}(\Lambda$ : half of multilayer periodicity length, $\mu \mathrm{m}$ )
4. The microhardness of the produced multilayered coatings was found to increase with the decrease of their periodicity length.

\section{Compliance with ethical standards}

Conflict of interest On behalf of all authors, the corresponding au- 
thor states that there is no conflict of interest.

\section{References}

1. Schweitz KO, Chevallier J, Bottiger J, Matz W, Schell N (2001) Hardness in $\mathrm{Ag} / \mathrm{Ni}, \mathrm{Au} / \mathrm{Ni}$ and Cu/Ni multilayers. Philos Mag A 81:2021

2. Jankowski A, Tsakalakos T (1996) Effects of deflection on bulge test measurements of enhanced modulus in multilayered films. Thin Solid Films 290-291:243

3. Panagopoulos CN, Papachristos VD, Wahlstrom U, Leisner P, Christoffersen LW (2000) Ni-P-W multilayered alloy coatings produced by pulse plating. Scripta Mater 43:677

4. Yogesha S, Chitharanjan Hegde A (2011) Optimization of deposition conditions for development of high corrosion resistant $\mathrm{Zn}-\mathrm{Fe}$ multilayer coatings. J Mater Process Technol 211(8):1409-1415

5. Thangaraj V, Ravishankar K, Chitharanjan Hegde A (2008) Surface modification by compositionally modulated multilayered $\mathrm{Zn}-\mathrm{Fe}$ alloy coatings. Chin J Chem 26:1-10

6. Rahsepar M, Bahrololoom ME (2009) Study of surface roughness and corrosion performance of $\mathrm{Ni} / \mathrm{Zn}-\mathrm{Fe}$ and $\mathrm{Zn}-\mathrm{Fe} / \mathrm{Ni}$ compositionally modulated multilayer coatings. Surf Coat Technol 204(5):580-585

7. Ramanauskas R, Juškėnas R, Kaliničenko A, Garfias-Mesias LF (2004) Microstructure and corrosion resistance of electrodeposited zinc alloy coatings. J Solid State Eletrochem 8:416

8. Lee K-K, Lee I-H, Lee C-R, Ahn H-K (2007) In-situ observation in a scanning electron microscope on the exfoliation behavior of galvannealed $\mathrm{Zn}-\mathrm{Fe}$ coating layers. Surf Coat Technol 201(14):6261-6266

9. Yang ZN, Zhang Z, Zhang JQ (2006) Electrodeposition of decorative and protective $\mathrm{Zn}$-Fe coating onto low-carbon steel substrate. Surf Coat Technol 200:4810

10. Ramanauskas R, Gudaviciute $L$, Diaz-Ballote $L$, Bartolo-Perez $P$, Quintana P (2001) Corrosion behaviour of chromated Zn and Zn alloy electrodeposits. Surf Coat Technol 140:109

11. Wilcox GD, Gabe DR (1993) Electrodeposited zinc alloy coatings. Corros Sci 35:1251

12. Ramanauskas $R$ (1999) Structural factor in Zn alloy electrodeposit corrosion. Appl Surf Sci 153:53

13. Boshkov N, Petrov K, Kovacheva D, Vitkova S, Nemska S (2005) Influence of the alloying component on the protective ability of some zinc galvanic coatings. Electochimica Acta 51:77

14. Panagopoulos CN, Georgarakis KG, Petroutzakou S (2005) Sliding wear behaviour of zinc-cobalt alloy electrodeposits. J Mater Proc Technol 160:234

15. Panagopoulos CN, Georgarakis KG, Agathocleous PE (2003) Sliding wear behaviour of zinc-nickel alloy electrodeposits. Tribol Int 36:619

16. Panagopoulos CN, Agathocleous PE, Papachristos VD, Michaelides A (2000) Sliding wear behaviour of zinc-iron alloy electrodeposits. Surf Coat Technol 123:62

17. Fei J, Wilcox GD (2006) Electrodeposition of zinc-nickel compositionally modulated multilayer coatings and their corrosion behaviours. Surf Coat Technol 200:3533

18. Ivanov I, Kirilova I (2003) Corrosion resistance of compositionally modulated multilayered $\mathrm{Zn}-\mathrm{Ni}$ alloys deposited from a single bath. J Appl Electrochem 33:239

19. Beltowska-Lehman E, Ozga P, Swiatek Z, Lupi C (2002) Electrodeposition of $\mathrm{Zn}-\mathrm{Ni}$ protective coatings from sulfate-acetate baths. Surf Coat Technol 151-152:444

20. Zhou Z, O'Keefe TJ (1997) Modification of anomalous deposition of $\mathrm{Zn-Ni}$ alloy by using tin additions. Surf Coat Technol 96:191

21. Kirilova I, Ivanov I, St. Rashkov (1998) Anodic behaviour of composition modulated $\mathrm{Zn}$-Co multilayers electrodeposited from single and dual baths. J Appl Electrochem 28:1359
22. Kirilova I, Ivanov I (1999) Corrosion behaviour of Zn-Co compositionally modulated multilayers electrodeposited from single and dual baths. J Appl Electrochem 29:1133

23. Boshkov N, Petrov K, Vitkova S, Nemska S, Raichevsky G (2002) Composition of the corrosion products of galvanic alloys $\mathrm{Zn}-\mathrm{Co}$ and their influence on the protective ability. Surf Coat Technol 157:171

24. Jensen JD, Gabe DR, Wilcox GD (1998) The practical realisation of zinc-iron CMA coatings. Surf Coat Technol 105:240

25. Liao Y, Gabe DR, Wilcox GD (1998) A study of Zn-Fe alloy electrodeposition using a rotating cylinder electrode hull cell. Plat Surf Finish 83:60

26. Yuan J, Yuan R, Wang J, Li Q, Xing X, Liu X, Wenbin H (2018) Fabrication and corrosion resistance of phosphate/ZnO multilayer protective coating on magnesium alloy. Surf Coat Technol 352:74-83

27. Shugurov AR, Kazachenok MS (2018) Mechanical properties and tribological behavior of magnetron sputtered TiAIN/TiAl multilayer coatings. Surf Coat Technol 353:254-262

28. Ge Y, Wang Y, Chen J, Zou Y, Guo L, Ouyang J, Jia D, Zhou Y (2018) Hot corrosion behavior of $\mathrm{NbSi}_{2} / \mathrm{SiO}_{2}-\mathrm{Nb}_{2} \mathrm{O}_{5}$ multilayer coating on Nb alloy. J Alloy Compd 767:7-15

29. Zhang H, Li Z, He W, Liao B, He G, Cao X, LiY (2018) Damage evolution and mechanism of TiN/Ti multilayer coatings in sand erosion condition. Surf Coat Technol 353:210-220

30. Huang B, Le W, Wang Y, Luo X, Yang Y (2019) Microstructure, properties and thermal stability of W/B4C multilayer coating synthesized by ion beam sputtering. Appl Surf Sci 464:10-20

31. Wang T, Jin Y, Bai L, Zhang G (2017) Structure and properties of NbN/MoN nano-multilayer coatings deposited by magnetron sputtering. J Alloy Compd 729:942-948

32. Li G, Sun J, Ye X, Yi X, Jiabin G, Wang L, Huang K, Liu K, Li L (2018) Microstructure, mechanical properties, and cutting performance of TiAISiN multilayer coatings prepared by HiPIMS. Surf Coat Technol 353:274-281

33. Chan Y-C, Chen H-W, Tsai Y-Z, Duh J-G, Lee J-W (2013) Texture, microstructure and anti-wear characteristics in isostructural $\mathrm{CrAl}-$ SiN/W2N multilayer coatings. Thin Solid Films 544:265-269

34. Torabinejad V, Aliofkhazraei M, Sabour Rouhaghdam A, Allahyarzadeh MH (2017) Tribological properties of Ni-Fe-Co multilayer coatings fabricated by pulse electrodeposition. Tribol Int 106:34-40

35. Shi K, Wang C, Gross C, Chung Y-W (2015) Reversing the inverse hardness-toughness trend using W/VC multilayer coatings. Surf Coat Technol 284:80-84

36. Chen Y-I, Zheng Z-T, Kai W, Huang Y-R (2017) Oxidation behavior of Ru-Al multilayer coatings. Appl Surf Sci 406:1-7

37. Yang YH, Wu FB (2016) Microstructure evolution and protective properties of TaN multilayer coatings. Surf Coat Technol 308:108-114

38. Cullity BD (1967) Elements of X-ray diffraction, 3rd edn. AddisonWesley Publishing Company, Boston, pp 259-263

39. Cammarata RC, Schlesinger TE, Kim C, Qadri SB, Edelstein AS (1990) Nanoindentation study of the mechanical properties of coppernickel multilayered thin films. Appl Phys Lett 56:1862

40. Hansen M (1958) Constitution of binary alloys, 2nd edn. Mc Graw Hill, New York

41. De Wit K, De Boeck A, De Cooman BC (1999) Study of the influence of phase composition and iron content on the formability characteristics of zinc-iron electroplated sheet steel. J Mater Eng Perform 8:531

42. Minggyuan G, Notis MR, Marder AR (1991) The effect of continuous heating on the phase transformations in zinc-iron electrodeposited coatings. Met Metall Trans A 22:1737 